\title{
Homoenxerto em cirurgia de valvas cardíacas: evidências para a prática da enfermagem perioperatória
}

\section{Homografts in cardiac valves surgery: evidences for the perioperative nursing practice}

\author{
Homoenxerto en la cirugía cardiaca, la válvula: las pruebas para la \\ práctica de la enfermería perioperatoria
}

Flávia Martinelli PelegrinoI, Fernanda Gaspar Torrati ${ }^{I I}$, Namie Okino SawadaIII, Cristina Maria Galvão ${ }^{\mathrm{IV}}$

\begin{abstract}
I Enfermeira. Mestranda do Programa de Pós-Graduação em Enfermagem Fundamental (PPGEF) da Escola de Enfermagem de Ribeirão Preto da Universidade de São Paulo (EERP/USP). Ribeirão Preto, SP. E-mail: flaviamp@eerp.usp.br.

II Enfermeira. Mestranda do PPGEF/EERP/USP. Ribeirão Preto, SP. E-mail: fertorrati@yahoo.com.br.

III Enfermeira. Professor do Departamento de Enfermagem Geral e Especializada da EERP/USP). Ribeirão Preto, SP. E-mail: crisgalv@eerp.usp.br.

IV Enfermeira. Professor do Departamento de Enfermagem Geral e Especializada da EERP/USP). Ribeirão Preto, SP. E-mail:
\end{abstract} sawada@eerp.usp.br.

\section{RESUMO}

O uso clínico de homoenxertos de valvas cardíacas é amplamente utilizado como técnica cirúrgica para várias doenças cardiovasculares. Dentre as atividades realizadas pela enfermagem há o descongelamento de homoenxerto no período intra-operatório de cirurgia cardíaca. Para fundamentar tal prática desenvolvemos o presente estudo. Este estudo tem como objetivo buscar na literatura as evidências disponíveis sobre os cuidados no descongelamento de homoenxertos em cirurgias de valvas cardíacas no período intra-operatório. Trata-se de uma revisão integrativa da literatura. As bases de dados selecionadas foram Medline e Lilacs e os descritores de assunto utilizados foram: transplante homólogo, criopreservação e valvas cardíacas. Foram incluídos na revisão sete artigos, os quais foram abordavam principalmente aspectos da técnica para o descongelamento do enxerto, o tempo para a realização deste procedimento e a solução empregada. Concluímos que a prática do descongelamento do homoenxerto fundamenta-se em estudos de nível de evidências 6 e 7 e abordaram pouco sobre a atuação da enfermagem.

Descritores: Transplante homólogo; Criopreservação; Valvas cardíacas.

\section{ABSTRACT}

Homograft cardiac valves are largely used as surgical technique for several cardiovascular diseases. Graft defrosting is among activities performed by nursing in cardiac surgeries in the intraoperative period. The development of this study aims to support such practice through the search, in the literature, of evidence available on the care of graft defrosting in homograft cardiac valves in the intraoperative period. It is an integrative literature review. The databases selected were Medline and Lilacs and the following descriptors were used: transplantation, homologous; cryopreservation and heart valves. Seven articles were included in the review, which mainly approached aspects of the graft defrosting technique, length of time for performing such procedure, and solution adopted. We concluded that the graft defrosting practice is based on studies of evidence level 6 and 7, and little has been discussed about the nursing practice.

Descriptors: Transplantation; Homologous; Cryopreservation; Heart valves.

\section{RESUMEN}

El uso clínico de homoinjerto de válvulas cardíacas se utiliza ampliamente como una técnica quirúrgica para diversas enfermedades cardiovasculares. Entre las actividades llevadas a cabo por la enfermería hay el descongelar del homoinjerto durante el intra-operatorio de cirugía cardíaca. Para fundamentar esta práctica hemos desarrollado el presente estudio. Este estudio tiene como objetivo examinar las pruebas disponibles la literatura sobre los cuidados en el descongelamiento de homoinjertos en cirugía de válvulas cardíaca, durante el intra-operatorio. Se trata de un revisión integrativa de la literatura. Las bases de datos seleccionadas fueron Medline y Lilacs y los descriptores fueron: trasplante homólogo, criopreservación y válvulas cardíacas. Fueron incluidos en la revisión siete artículos, los cuales abordaban principalmente los aspectos de la técnica para el descongelamiento del injerto, el tiempo para llevar a cabo este procedimiento y la solución empleada. Llegamos a la conclusión de que la práctica de la descongelación de homoinjerto se basa en estudios de nivel de evidencias 6 y 7 y abordaran poco acerca de la actuación de la enfermería.

Descriptores: Trasplante homólogo; Criopreservación; Válvulas Cardíacas. 


\section{INTRODUÇÃO}

O uso clínico de homoenxertos de valvas cardíacas é amplamente utilizado como técnica cirúrgica para várias doenças cardiovasculares podendo ser obtido da valva aórtica, frequentemente usado em doenças como destruição valvar, endocardite e estenose congênita do ventrículo esquerdo; da valva pulmonar sendo indicado para a correção da regurgitação ventricular direita e durante a cirurgia de "Ross" e homoenxerto da valva mitral que é o menos frequente ${ }^{(1-2)}$.

$\mathrm{Na}$ literatura estudos demonstram que os pacientes que receberam homoenxertos apresentaram um excelente perfil hemodinâmico, aproximando ao fisiológico, não requerendo tratamento com anticoagulantes e com incidência quase nula de tromboembolismo, maior resistência à infecção e durabilidade satisfatória( ${ }^{(3-4)}$. Esses resultados clínicos acarretaram melhor qualidade de vida no pós-operatório e maior sobrevida dos pacientes ${ }^{(5)}$.

Porém, as dificuldades de obtenção de doadores, as técnicas pouco eficazes de esterilização, preservação e estocagem, a preocupação com transmissão de doenças infecto-contagiosas e o desenvolvimento de próteses mecânicas e biológicas heterólogas representaram limitações no uso de homoenxertos ${ }^{(4-5)}$.

Apenas nos anos 60, com o desenvolvimento da criopreservação ressurgiu $O$ interesse no uso dos homoenxertos ${ }^{(4,6)}$. A criopreservação representou o aperfeiçoamento da preservação tecidual e o aumento da disponibilidade de enxertos para transplantes podendo ser definida como a preservação de células, tecidos, órgãos ou embriões por meio de congelamento, permitindo a manutenção da forma, da estrutura e da composição química existente, de todos os elementos constituintes das amostras $^{(7)}$.

Atualmente a utilização de criopreservação é empregada de forma rotineira com pequenas modificações técnicas, por diversos bancos de tecidos cardiovasculares do mundo, sendo considerada, até hoje, como a mais eficiente para o processamento e estocagem de homoenxertos valvares ${ }^{(5-6,8-9)}$. No Brasil, este serviço é desenvolvido pelo Banco de Valvas Cardíacas Humanas da Santa Casa de Misericórdia de Curitiba desde 1996.

O processo de criopreservação inclui quatro etapas fundamentais: esterilização, congelamento, armazenamento e descongelamento. Os homoenxertos são "esterilizados" em solução nutriente (RPMI) contendo antibióticos com largo espectro (por exemplo, cefoxitina, lincomicina, polimixina B e vancomicina) por 12-24 horas. Em seguida, são congelados de maneira gradativa e controlada a $-1^{\circ} \mathrm{C} / \mathrm{min}$ em uma nova solução de nutriente (RPMI + soro fetal bovino $10 \%$ ou M199) contendo crioprotetores (substâncias que previnam a formação de cristais de gelo dentro das células durante o descongelamento). O dimetilsulfóxido (DSMO) e o glicerol são os crioprotetores mais comumente empregados. Os homoenxertos criopreservados a $-196^{\circ} \mathrm{C}$ são armazenados em freezer de nitrogênio líquido até o momento do transplante. Durante o descongelamento é produzido a rehidratação das células do homoenxerto realizada durante o período intra-operatório. É uma etapa crucial, pois se for conduzida de forma inapropriada pode levar a destruição das células ${ }^{(3,8,10-11)}$.

A enfermagem tem atuação marcante no processo de descongelamento de homoenxertos no período intra-operatório. Dentre as atividades realizadas pela enfermagem neste processo destacamos: a escovação das mãos, a paramentação cirúrgica, o preparo da mesa cirúrgica auxiliar com os instrumentais e materiais estéreis necessários, aquecimento e manutenção da temperatura do soro utilizado para o descongelamento, dentre outros procedimentos. Esta realidade é frequentemente vivenciada pelas autoras deste estudo enquanto enfermeiras em unidade de centro cirúrgico de um hospital governamental do interior do Estado de São Paulo.

Frente à importância de executar de forma adequada o processo de descongelamento de homoenxertos realizamos o presente estudo com o objetivo de buscar na literatura as evidências disponíveis sobre os cuidados com homoenxertos em cirurgias de valvas cardíacas no período intraoperatório para o desenvolvimento desta prática com fundamentação científica.

\section{MÉTODO}

A fim de atingir o objetivo proposto optamos por realizar uma revisão integrativa da literatura. Esse método de pesquisa permite buscar, reunir e sintetizar as pesquisas já concluídas sobre o tema de interesse. Uma revisão integrativa realizada de forma adequada exige os mesmos padrões de rigor, clareza e replicação utilizados nos estudos primários ${ }^{(12)}$.

Para a elaboração da revisão integrativa adotamos os seguintes passos: seleção da questão temática; estabelecimento de critérios de inclusão e exclusão de artigos (seleção da amostra); definição dos dados a serem extraídos dos artigos selecionados; análise dos dados; interpretação dos resultados e por último a apresentação da revisão. Esses passos foram empregados de acordo com os estudiosos deste método de pesquisa(13-14).

A questão norteadora da revisão integrativa foi: qual é o conhecimento científico produzido sobre os cuidados no descongelamento de homoenxertos em 
cirurgias de valvas cardíacas no período intraoperatório?

As bases de dados utilizadas foram: Medical Literature Analysis and Retrieval Sistem on line (MEDLINE) e Literatura Latino Americana e do Caribe em Ciências da Saúde (LILACS). Com base em leituras prévias e no objetivo deste estudo estabelecemos os seguintes descritores de assunto: transplante homólogo, criopreservação e valvas cardíacas.

Os critérios de inclusão para seleção dos artigos foram: artigos publicados em português, inglês ou espanhol, com resumos disponíveis nas bases de dados, artigos publicados no período de 1997 a 2009, que abordassem sobre homoenxertos e cirurgia cardíaca, independente do tipo de estudo. Os artigos não disponíveis no Brasil foram excluídos, bem como aqueles que utilizaram animais como amostra da pesquisa.

A estrutura da busca foi efetuada primeiramente com os três descritores juntos em cada base de dados. Assim, ao empregarmos os descritores transplante homólogo, criopreservação e valvas cardíacas, obtivemos nenhum artigo na LILACS e 41 na MEDLINE. Uma nova busca foi realizada apenas na base de dados LILACS com o uso combinatório dos descritores. Ao utilizarmos os descritores transplante homólogo e criopreservação obtivemos oito artigos; transplante homólogo e valvas cardíacas dois artigos; criopreservação e valvas cardíacas um artigo.

Dos 52 artigos encontrados, alguns se repetiram e outros abordavam como enfoque o transplante de tecidos ósseos, sendo estes excluídos. Frente aos critérios de inclusão foram selecionados 16 artigos, sendo 13 indexados ao MEDLINE e 3 ao LILACS. Porém, após a leitura dos 16 artigos na íntegra, sete artigos foram excluídos por não abordarem 0 descongelamento de homoenxertos. Assim, nove artigos foram incluídos neste estudo, sendo seis da base de dados MEDLINE e três da LILACS.

Os artigos receberam numeração conforme foram sendo localizados e para a extração dos dados utilizamos um instrumento validado por Ursi(15). Esse instrumento contempla os seguintes itens: identificação, instituição sede do estudo, tipo de revista científica, características metodológicas do estudo e avaliação do rigor metodológico.

A análise dos dados ocorreu de forma descritiva e construímos tabelas para apresentar a síntese dos artigos incluídos na revisão. Para a avaliação do nível de evidência dos estudos utilizamos como referencial a classificação de Melnyk e Fineout-Overholt(16) e para o delineamento de pesquisa os conceitos definidos por Polit, Beck e Hungler(17).

\section{RESULTADOS E DISCUSSÃO}

O tema homoenxertos de valvas cardíacas foi predominantemente publicado em revistas médicas relacionadas à área de cardiologia (seis artigos), os anos de 2004, 2006 e 2008 obtiveram o maior número de publicações (dois artigos, respectivamente), sendo que nos anos de 1998, 2002 e 2005 encontramos apenas um artigo publicado.

Em relação aos países que publicaram os artigos, a Europa foi o continente com o maior número de publicações (quatro artigos), seguido do Brasil (três artigos), Índia (um artigo) e Estados Unidos da América (um artigo).

Dos nove artigos incluídos na revisão, dois artigos têm o delineamento de pesquisa quaseexperimental, cinco têm o delineamento de pesquisa não-experimental e o tipo do estudo é descritivoexploratório e dois artigos são relatos de experiência. De acordo com a classificação de Melnyk e FineoutOverholt(16), os estudos com delineamento de pesquisa não-experimental são classificados com nível de evidência seis e estudos oriundos de opinião de autoridades e/ou relatório de comitês de especialistas são considerados com nível de evidência sete, os quais retratam estudos de evidências fracas para a prática clínica. Apenas incluímos dois estudos considerados com nível de evidência forte, o qual é uma investigação laboratorial com delineamento de pesquisa quase-experimental classificado com nível de evidência três.

A leitura dos artigos desta revisão integrativa permitiu identificar que a técnica para a realização do descongelamento de homoenxertos de valvas cardíacas; o tempo para a realização do descongelamento e a solução usada para o descongelamento são os aspectos principais durante o intra-operatório de cirurgia de valva cardíaca. As sínteses desses aspectos estão descritos no Quadro1. 
Quadro 1: Síntese dos artigos sobre a técnica, o tempo e a solução para o descongelamento de homoenxertos - Ribeirão Preto - 2009.

\begin{tabular}{|c|c|c|}
\hline Estudo & Objetivo & $\begin{array}{c}\text { Resultados } \\
\end{array}$ \\
\hline $\begin{array}{l}\text { Da Costa et al(18) } \\
\text { Relato de experiência } \\
\text { Nível de evidência: } 7\end{array}$ & $\begin{array}{l}\text { Discutir a indicação clínica, técnica cirúrgica e } \\
\text { resultados de homoenxertos aórticos com enfoque } \\
\text { no preparo, esterilização, estocagem, enxágüe e } \\
\text { descongelamento. }\end{array}$ & $\begin{array}{l}\text { No Prince Charles Hospital: técnica asséptica com banhos graduais de forma suave com } \\
\text { descongelamento de } 10 \text { a } 15 \text { minutos em solução salina estéril a } 40^{\circ} \mathrm{C} \text {. } \\
\text { University of Alabama: homoenxerto envolvido em um pacote é banhado cuidadosamente em } \\
\text { solução salina a } 42^{\circ} \mathrm{C} \text { e após remoção da embalagem, este homoenxerto é colocado em meio de } \\
\text { cultura do tecido a } 42^{\circ} \mathrm{C} \text {. Os autores não citam o tempo gasto para a execução do procedimento. } \\
\text { Banco de Tecidos de Homoenxertos Comerciais: colocar o pacote do enxerto em bacia estéril } \\
\text { utilizando } 2 \text { litros de solução salina estéril a } 37-42^{\circ} \mathrm{C} \text { para banho de } 8 \text { a } 10 \text { minutos. Após } \\
\text { remover o enxerto do pacote é feito banhos com } 1 \text { litro de Solução de Ringer Lactato (SRL) e } 5 \% \\
\text { dextrose de } 1 \text { a } 2 \text { minutos. O manuseio do enxerto deve ser feito de modo gentil auxiliado por } \\
\text { fórceps estéril. }\end{array}$ \\
\hline $\begin{array}{l}\text { Costa et al(5) } \\
\text { Descritivo- exploratório } \\
\text { Nível de evidência: } 6\end{array}$ & $\begin{array}{l}\text { Avaliar o funcionamento do Banco de Valvas } \\
\text { Cardíacas Humanas frente às atividades de } \\
\text { captação, processamento, armazenamento e } \\
\text { distribuição de enxertos homólogos } \\
\text { cardiovasculares. }\end{array}$ & $\begin{array}{l}\text { Pessoas treinadas foram autorizadas a descongelar e diluir a solução crioprotetora dos enxertos } \\
\text { criopreservados. O descongelamento foi feito de forma rápida com soro fisiológico a } 42-50^{\circ} \mathrm{C} \\
\text { seguido de diluição gradual do crioprotetor com solução nutriente de RPMI } 1640 \text { e } 10 \% \text { de soro } \\
\text { fetal bovino. }\end{array}$ \\
\hline $\begin{array}{l}\text { Verghese et al(6) } \\
\text { Descritivo- exploratório } \\
\text { Nível de evidência: } 6\end{array}$ & $\begin{array}{l}\text { Descrever a experiência do banco de válvula } \\
\text { cardíaca relacionada à indicação, uso e } \\
\text { processamento } \\
\text { /descongelamento de homoenxertos valvulares. }\end{array}$ & $\begin{array}{l}\text { A embalagem externa da bolsa é aberta pelo circulante de sala que entrega ao instrumentador } \\
\text { cirúrgico, o qual coloca em uma bacia com água estéril a } 40^{\circ} \mathrm{C} \text { para o rápido descongelamento } \\
\text { por } 5 \text { a } 10 \text { minutos. Então a embalagem interna da válvula é cortada e feita outro enxágüe em } 5 \\
\text { minutos em solução de M199 com } 5 \% \text { DMSO. }\end{array}$ \\
\hline $\begin{array}{l}\text { Gerola et al }{ }^{(4)} \\
\text { Descritivo- exploratório } \\
\text { Nível de evidência: } 6\end{array}$ & $\begin{array}{l}\text { Analisar os resultados imediatos, clínicos e } \\
\text { ecocardiográficos, com o uso do homoenxerto } \\
\text { aórtico criopreservado no tratamento cirúrgico da } \\
\text { valva aórtica. }\end{array}$ & O descongelamento na sala de operação é realizado em 15 min (descongelamento rápido). \\
\hline $\begin{array}{l}\text { Costa et al (3) } \\
\text { Descritivo-exploratório } \\
\text { Nível de evidência: } 6\end{array}$ & $\begin{array}{l}\text { Avaliar os resultados imediatos e em curto prazo } \\
\text { da substituição da valva mitral por homoenxerto } \\
\text { mitral criopreservado. }\end{array}$ & $\begin{array}{l}\text { Na hora da operação, o homoenxerto selecionado é descongelado de forma rápida e são usadas } \\
\text { soluções salinas aquecidas e com concentrações decrescentes de dimetilsulfóxido (DMSO). }\end{array}$ \\
\hline $\begin{array}{l}\text { Kitagawa et al (11) } \\
\text { Relato de experiência } \\
\text { Nível de evidência: } 7\end{array}$ & $\begin{array}{l}\text { Revisão bibliográfica buscando evidências de que } \\
\text { a criopreservação é o melhor método atual para } \\
\text { armazenamento de homoenxertos de valvas } \\
\text { cardíacas. }\end{array}$ & O tempo para o descongelamento é de 12-14 minutos para valva aórtica e pulmonar. \\
\hline $\begin{array}{l}\text { Krs et al (9) } \\
\text { Descritivo-exploratório } \\
\text { Nível de evidência: } 3\end{array}$ & $\begin{array}{l}\text { Analisar fatores de impacto sobre a morfologia } \\
\text { tecidual dos homoenxertos de valvas cardíacas } \\
\text { por meio da avaliação dos protocolos de } \\
\text { processamento e preservação de bancos de } \\
\text { tecidos de valvas cardíacas. }\end{array}$ & $\begin{array}{l}\text { O enxágüe de homoenxertos com solução salina provocou destruição endotelial durante o } \\
\text { procedimento de descongelamento. Assim, recomenda-se evitar até mesmo em curto prazo a } \\
\text { lavagem salina de homoenxertos e utilizar a solução de preservação de órgãos para transplantes. }\end{array}$ \\
\hline $\begin{array}{l}\text { Mirabet et al (19) } \\
\text { Descritivo-exploratório } \\
\text { Nível de evidência: } 6\end{array}$ & $\begin{array}{l}\text { Analisar o efeito do tempo de armazenamento } \\
\text { sobre a estrutura, integridade e à viabilidade de } \\
\text { homoenxertos de valvas cardíacas criopreservadas } \\
\text { em nitrogênio líquido. }\end{array}$ & $\begin{array}{l}\text { O homoenxerto foi criopreservado em um bolsa de alumínio "Kapton-teflon" com solução } \\
\text { conservante ( } 50 \mathrm{ml} \text { de } \mathrm{M} 199,5 \% \text { de albumina e } 10 \% \text { Me } 2 \mathrm{SO} \text { ) e selado por calor, para melhorar a } \\
\text { troca de calor durante o congelamento e descongelamento. O descongelamento foi realizado por } \\
\text { imersão em água a } 42^{\circ} \mathrm{C} \text {. por } 12 \text { às } 24 \text { h seguido de enxágües a temperatura ambiente de } 2-3 \\
\text { min. A seguir a solução conservante do homoenxerto foi removida por diluição contínua de } \\
\text { soluções de M199 contendo albumina humana } 5 \% \text {. Com este processo há diminuição de fissuras } \\
\text { nos tecidos das valavas cardíacas. }\end{array}$ \\
\hline $\begin{array}{l}\text { Burket et al }{ }^{(20)} \\
\text { Descritivo-exploratório } \\
\text { Nível de evidência: } 3\end{array}$ & $\begin{array}{l}\text { Avaliar o impacto do protocolo de processamento } \\
\text { de valvas cardíacas para homoenxertos sobre a } \\
\text { morfologia tecidual. }\end{array}$ & $\begin{array}{l}\text { Foi observado efeito negativo para o descongelamento de homoenxerto com solução salina. Os } \\
\text { autores recomendam evitar o uso de solução salina para a lavagem do homoenxerto até mesmo } \\
\text { em curto prazo e indicam preferencialmente o uso de soluções especificas atualmente empregada } \\
\text { na conservação de órgãos para transplantes. }\end{array}$ \\
\hline
\end{tabular}


O conhecimento sobre os cuidados no descongelamento de homoenxertos em cirurgias de valvas cardíacas no período intra-operatório identificados na revisão integrativa envolve a técnica para a realização do descongelamento; o tempo para a realização do descongelamento e a solução usada para o descongelamento.

No entanto, estes cuidados para o descongelamento de homoenxertos são norteados por protocolos desenvolvidos por instituições hospitalares, entendida aqui como, hospitais e banco de tecidos. Estes protocolos têm aspectos comuns e divergentes entre as instituições e a prática de descongelamento de homoenxertos desenvolvida no hospital que atuamos.

Dentre os pontos comuns temos que o tempo total para a realização do descongelamento do homoenxerto deverá ser entre 10 a 15 minutos com a utilização de solução a uma temperatura em torno de $40^{\circ} \mathrm{C}$. O descongelamento se processará com banhos graduais sendo a sua manipulação de modo cuidadoso e suave.

A solução utilizada para o descongelamento de homoenxertos foi o ponto de divergência entre os artigos selecionados. Algumas instituições usam solução salina para o descongelamento de homoenxertos durante o período intra-operatório de cirurgia de valva cardíaca, outras usam solução de ringer lactato e dextrose. No entanto, o estudo de $\mathrm{Krs}^{(9)}$ e de Burket$^{(20)}$ concluíram que há uma destruição do endotélio durante o descongelamento do homoenxerto com solução salina e recomenda a utilização de soluções específicas para a preservação de tecidos/órgãos humanos a fim de preservar a morfologia tecidual.

A técnica de descongelamento é tão importante quanto à técnica de criopreservação, pois qualquer erro pode levar à perda do enxerto e danos sérios ao paciente, incluindo o descongelamento inapropriado levando a uma alteração na morfologia tecidual e até a não realização da operação por falta do enxerto compatível.

Alguns artigos têm por objetivo analisar a viabilidade dos homoenxertos, como exposto por Kitagawa11); entretanto, não citam o papel do profissional responsável pelo descongelamento que está diretamente ligado a essa viabilidade.

Por outro lado, os textos que citam o profissional responsável pelo descongelamento não dão ênfase à categoria e a maioria não explicita qual é o profissional responsável por este procedimento, apenas Verghese ${ }^{(6)}$ identifica-o como sendo 0 circulante de sala e o instrumentador cirúrgico.

Os cuidados, em nosso serviço iniciam-se desde o recebimento dos homoenxertos vindos do Banco de Homoenxertos Valvares da Santa Casa de Curitiba, acondicionamento destes até a sua utilização em sala operatória, ou seja, o descongelamento propriamente dito, envolvendo nesta fase, enfermeiros e/ou instrumentadores cirúrgicos. Outro ponto importante é o conhecimento sobre a dimensionalidade das valvas cardíacas uma vez que para o processo de descongelamento do homoenxerto a primeira informação necessária é o tamanho da válvula a ser selecionada para a realização do implante do homoenxerto. Para tanto, todos os requisitos de se realizar este procedimento em sala operatória, como escovação cirúrgica das mãos, paramentação cirúrgica, instrumentais necessários, montagem da mesa para realização do descongelamento, soluções, e por fim, a técnica em si é de responsabilidade do enfermeiro e/ou instrumentador cirúrgico. Cabe ressaltar que a técnica para o descongelamento de homoenxertos realizada em nosso serviço é desenvolvida por enfermeiros e/ou instrumentador cirúrgico previamente treinados por enfermeiros do Banco de Homoenxertos Valvares da Santa Casa de Curitiba sendo todos os passos norteados por protocolo dessa instituição.

Salientamos ainda que alguns aspectos do descongelamento de homoenxertos de valvas cardíacas não foram contemplados nos artigos incluídos nesta revisão para subsidiar a prática desenvolvida em nosso serviço. Esse aspecto indica a existência de lacunas no conhecimento gerando a necessidade de novos estudos, principalmente para a realidade brasileira.

Os artigos selecionados apenas indicam o descongelamento de homoenxertos no período intraoperatório se referindo ao procedimento em si, não se atendo aos cuidados necessários para a viabilidade do homoenxerto.

\section{CONCLUSÃO}

A revisão integrativa sobre os cuidados no descongelamento de homoenxertos em cirurgias de valvas cardíacas no período intra-operatório permitiu identificar evidências sobre a técnica, tempo e solução para realização de tal procedimento. As recomendações para a execução desta prática são:

- técnica asséptica;

- utilização de materiais e instrumentais estéreis;

- o descongelamento deve ser feito de forma rápida, sendo o tempo limite de 15 minutos;

- e com soluções variadas.

Porém a maioria dessas recomendações foi fundamentada em estudos de evidências de nível seis e sete, sendo apenas dois estudos com nível de evidência três. Percebemos que tal procedimento está embasado em protocolos institucionais (Bancos de Tecidos) e que apenas um estudo da Índia cita o enfermeiro como participante do descongelamento. Já em nossa realidade, tal procedimento poderá ser 
realizado apenas por enfermeiros e/ou instrumentadores cirúrgicos mediante treinamento prévio fornecido por enfermeiras do Banco de Valvas Cardíacas, único no Brasil.

Diante desses resultados recomendamos a realização de pesquisas com delineamentos que permitam um nível de evidência mais forte, como os estudos clínicos randomizados controlados com participação dos enfermeiros.

\section{REFERÊNCIAS}

1. Ohkado A, Hachida M, Hoshi $H$, Nonoyama $M$, Saitou S, Bonkohara $Y$, et al. Problems in preservation of allogeneic heart values and vessels. Transplant Proc. 1999;31(5):2047-8.

2. Raanani E, Groysman M, Erez E, Berman M, Kogan A, Aravot D, et al. Establishment of a heart valve homograft bank using existing facilities. Transplant Proc. 2003;35(2):634-5.

3. Costa FDA, Abuchaim D, Haggi FH, Poffo R, Gaspar R, Rosa GS, et al. Homoenxerto mitral: uma realidade. Rev Bra Cir Cardiovasc. 1998;13(3):20210.

4. Gerola LR, Araújo WK, Hyong C, Silva GEF, Pereira Filho A, Vargas GF, et al. Homoenxerto aórtico criopreservado no tratamento cirúrgico das lesões da valva aórtica: resultados imediatos. Arq Bras Cardiol. 2004;83(4):280-87.

5. Costa MTBA, Costa FDA, Nazareno LCF, Domchoski J, Peruzzo AM, Colatusso $C$, et al. Análise das atividades dos oito anos iniciais do Banco de Valvas Cardíacas Humanas do Hospital de Caridade da Irmandade da Santa Casa de Misericórdia de Curitiba. Braz J Cardiovasc Surg. 2005;20(4):398-407.

6. Verghese S, Padmaja P, Sindhu B, Elizabeth SJ, Lesley $N$, Cherian KM. Homograft valve bank: our experience in valve banking. Indian Heart. 2004;56(4):299-306.

7. Descritores em Ciências da Saúde [Internet]. São Paulo: Centro Latino-Americano e do Caribe de Informação em Ciências da Saúde (BR) [uptade 2007 jan 20, cited 2007 jan 25]. Available from: http://decs.bvs.br/ .

8. Hoezl AC. Substituição da aorta abdominal de cães por homoenxerto criopreservado: análise histológica [dissertation]. Curitiba: Ciências da Saúde/UFPR; 2000. $51 \mathrm{p}$.

9. Krs O, Burkert J, Slízová D, Kobylka P, Spatenka J. Allograft semilunar cardiac valves processing and cryopreservation - morphology in scanning electron microscope. Cell Tissue Bank. 2006;7(3):67-73.

10. Mascaró J. Reemplazo valvular aórtico: criopreservación de homoinjertos. Rev Méd Clín Condes. 1998;9(3):97-101.

11. Kitagawa T, Masuda $\mathrm{Y}$, Tominaga T, Kano $\mathrm{M}$. Cellular biology of cryopreserved allograft valves. J Med Invest. 2001;48(3-4):123-32.
12. Beyea SC, Nicoll LH. Writing an integrative review. AORN J. 1998;67(4):877-80.

13. Broome ME. Integrative literature reviews for the development of concepts. Concept development in nursing: foundations, techniques and applications. Philadelphia: WB Saunders Company; 2000. p. 23150.

14. Whittemore $\mathrm{R}, \mathrm{Knafl} \mathrm{K}$. The integrative review: update methodology. J Adv Nurs. 2005;52(5):54653.

15. Ursi ES. Prevenção de lesões de pele no perioperatório: revisão integrativa da literatura [dissertation]. Ribeirão Preto: Escola de Enfermagem de Ribeirão Preto/USP; 2005. 128p.

16. Melnyk BM, Fineout-Overholt E. Making the case for evidence-based practice. Evidence-based practice in nursing \& healthcare. A guide to best practice. Philadelphia: Lippincott Williams \& Wilkins; 2005. p.3-24.

17. Polit DF, Beck CT, Hungler BF. Fundamentos de pesquisa em enfermagem: métodos, avaliação e utilização. Porto Alegre: Artmed; 2004.

18. Da Costa ML, Ghofaili FA, Oakley RM. Allograft tissue for use in valve replacement. Cell Tissue Bank. $2006 ; 7(4): 337-48$.

19. Mirabet V, Carda C, Solves P, Novella-Maestre E, Carbonell-Uberos F, Caffarena JM, et al. Long-term storage in liquid nitrogen does not affect cell viability in cardiac valve allografts. Cryobiology. 2008;57(2):113-21.

20. Burkert J, Krs O, Vojácek J, Mokrácek A, Slízová D, Hlubocky J, et al. Cryopreserved semilunar heart valve allografts: leaflet surface damage in scanning electron microscopy. Zentralbl Chir. 2008;133(4):367-73.

Artigo recebido em 24.09.08.

Aprovado para publicação em 03.07.09.

Artigo publicado em 31.12.09. 